\title{
REKAYASA KAMERA VIRTUAL PADA PERANGKAT LUNAK ADOBE FLASH
}

\author{
Jenisa Felisa \\ Sekolah Tinggi Manajemen Informatika dan Komputer LIKMI \\ Jl. Ir. H. Juanda no 96 Bandung \\ jenisafelisa@gmail.com
}

\begin{abstract}
ABSTRAK
Penelitian bertujuan untuk melakukan rekayasa kamera virtual (virtual camera / v-cam) yang digunakan untuk mempermudah pengguna perangkat lunak Adobe Flash dalam memanipulasi keadaan sudut pandang kamera dalam sebuah animasi. Rekayasa virtual camera dilakukan dengan memasukkan source code untuk pengaturan suatu objek dalam Adobe Flash sehingga dapat berfungsi sebagai kamera pada animasi di lembar kerja. Source code dijalankan dalan jenis file ActionScript 3.0 dalam perangkat lunak Adobe Flash.
\end{abstract}

Kata kunci : V-Cam, sudut pandang kamera, Adobe Flash, ActionScript, Animasi.

\section{PENDAHULUAN}

Adobe Flash merupakn sebuah perangkat lunak yang sangat populer digunakan untuk membuat animasi frame by frame. Semua ragam pengerjaan animasi dapat dikerjakan menggunakan Adobe Flash, mulai dari animasi sederhana (contohnya seperti video bersifat slide), atau video interaksi, dan bahkan animasi yang kompleks. Animasi tentunya dapat dikelompokan dalam banyak jenis dari berbagai kategori (berdasarkan bentuk karakter, teknik pembuatan, dan lainnya). Intinya dalam setiap jenis animasi diperlukan manipulasi-manipulasi tertentu agar hasil animasi dapat menyampaikan informasi yang diperlukan sesuai dengan tujuan pembuatan animasi tersebut, untuk itu banyak hal yang dapat diperhatikan dalam proses pembuatan animasi seperti proses penyocokan audio dengan gerakan tubuh karakter (dubbing), penggunaan video, gambar pendukung, gerakan-gerakan karakter atau objek animasi yang melibatkan masing-masing hint atau bagian dari objek secara mendetil, pengaturan kamera virtual (v-cam) pada animasi, dan masih banyak hal lainnya.

Penambahan v-cam dalam sebuah animasi merupakan sebuah teknik animasi lanjut yang dapat membuat antisipasi timing pada sebuah scene menjadi lebih dinamis. Dalam Adobe Flash belum disediakan secara langsung fitur seperti virtual kamera, fitur kamera hanya dapat diakses secara langsung untuk pengguna Adobe Animate yang mana merupakan versi upgrade dari Adobe Flash. Sebenarnya banyak trik yang dapat dilakukan untuk memperlihatkan pergerakan sudut pandang yang seolah-olah seperti kamera dalam Adobe flash seperti mengatur tween untuk ukuran semua objek (diperbesar atau diperkecil), pemakaian teknik masking dan teknik-teknik lainnya. Hanya saja jika dilakukan secaraa manual seperti itu, konsistensi semua objek mulai dari ukuran, posisi, bentuk akan berubah-ubah. Hal tersebut sangat tidak fleksibel dan butuh waktu ekstra untuk memperhatikan detil semua objek, terlebih lagi untuk pengerjaan animasi yang kompleks dengan melibatkan banyak layer dan objek. Maka itu penggunaan objek v-cam pada Adobe Flash akan sangat mempermudah animator dan dapat menghemat waktu pengerjaan animasi dalam hal mengatur sudut pandang kamera. 


\section{ANIMASI}

Setiawan ${ }^{[3]}$ menjelaskan bahwa animasi sendiri berasal dari bahasa latin yaitu "anima" yang berarti jiwa, hidup, semangat. Sedangkan karakternya adalah orang, hewan maupun objek nyata lainnya yang dituangkan dalam bentuk gambar 2D maupun 3D. sehingga karakter animasi secara dapat diartikan sebagai gambar yang memuat objek yang seolah-olah hidup, disebabkan oleh kumpulan gambar itu berubah beraturan dan bergantian ditampilkan. Objek dalam gambar bisa berupa tulisan, bentuk benda, warna dan spesial efek.

Animasi Menurut Fernandes ${ }^{[2]}$ didefinisikan sebagai berikut : "Animation is the process of recording and playing back a sequence of stills to achieve the illusion of continues motion."

Intinya animasi adalah suatu usaha untuk menghidupkan dan menggerakkan sesuatu yang tidak bisa bergerak sendiri.

\section{KONSEP V-CAM ADOBE FLASH}

Kamera virtual atau yang sering disebut sebagai v-cam (Virtual Camera) mengadaptasikan konsep sudut pandang orang ketiga dalam sebuah animasi ${ }^{[1]}$, dimana orang ketiga yang dimaksud adalah penonton dari animasi yang ditampilkan. Dalam Adobe Flash, konsep v-cam dilakukan dengan use case yang dapat dilihat pada gambar 1.

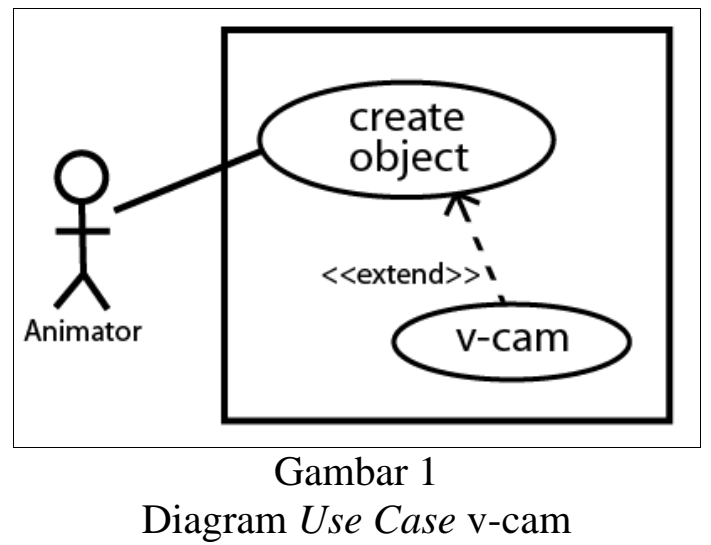

V-cam merupakan sebuah fitur optional yang bersifat extend terhadap use case create object dalam perangkat lunak Adobe Flash sehingga v-cam bisa dikatakan sebagai fitur tambahan yang memang tidak wajib disertakan dalam sebuah animasi. Animasi dapat dijalankan tanpa harus menyertakan virtual kamera.

Animator dapat menambahkan fitur v-cam dengan langkah-langkah berikut :

a. Membuka atau membuat lembar kerja dalam perangkat lunak Adobe Flash yang berjenis Flash File (ActionScript 3.0), buatlah sebuah layer baru pada bagian timeline khusus untuk menampung objek v-cam.

b. Dalam layer baru, buat sebuah objek berbentuk persegi yang dimensi ukurannya sama dengan dimensi ukuran lembar kerja yang dibuka, akan lebih mudah jika stroke color hitam, fill color putih (alfa 10\%). 


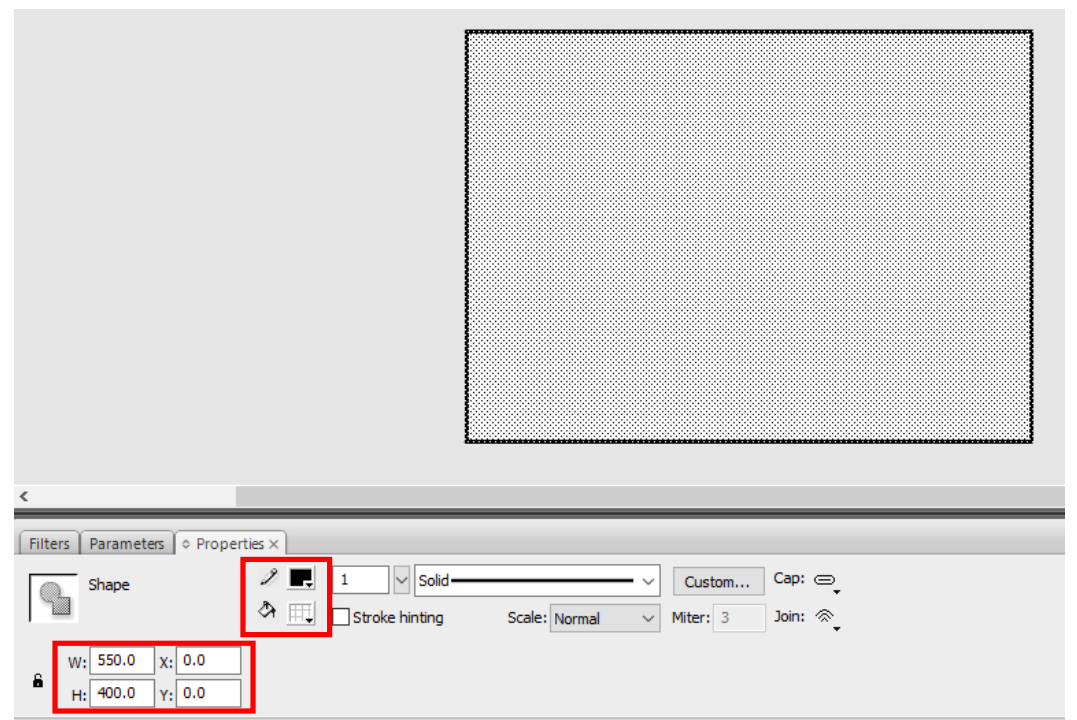

Gambar 2

Pengaturan tab properties pada objek persegi

c. Klik kanan pada objek kotak, pilih opsi "Convert to Symbol", masukkan nama, pilih tipe movie clip, registration di titik tengah, lalu tekan tombol "OK".

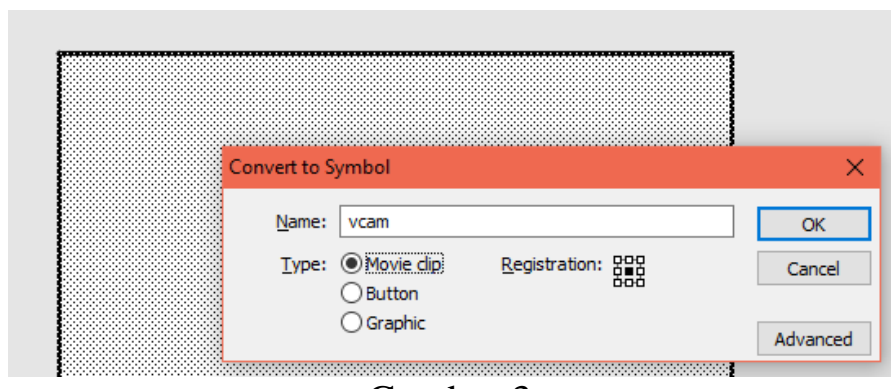

Gambar 3

Pengaturan Convert to Symbol objek v-cam

d. Klik 2x untuk masuk kedalam scene movie clip v-cam, lalu klik pada bagian luar objek v-cam, masuk dalam tab Actions di bagian bawah, atau jika tidak muncul tab Actions, pilih menu Window, klik opsi Actions (shortcut F9). Masukkan source code berikut pada kotak dialog Action seperti yang dapat dilihat pada gambar 4. 


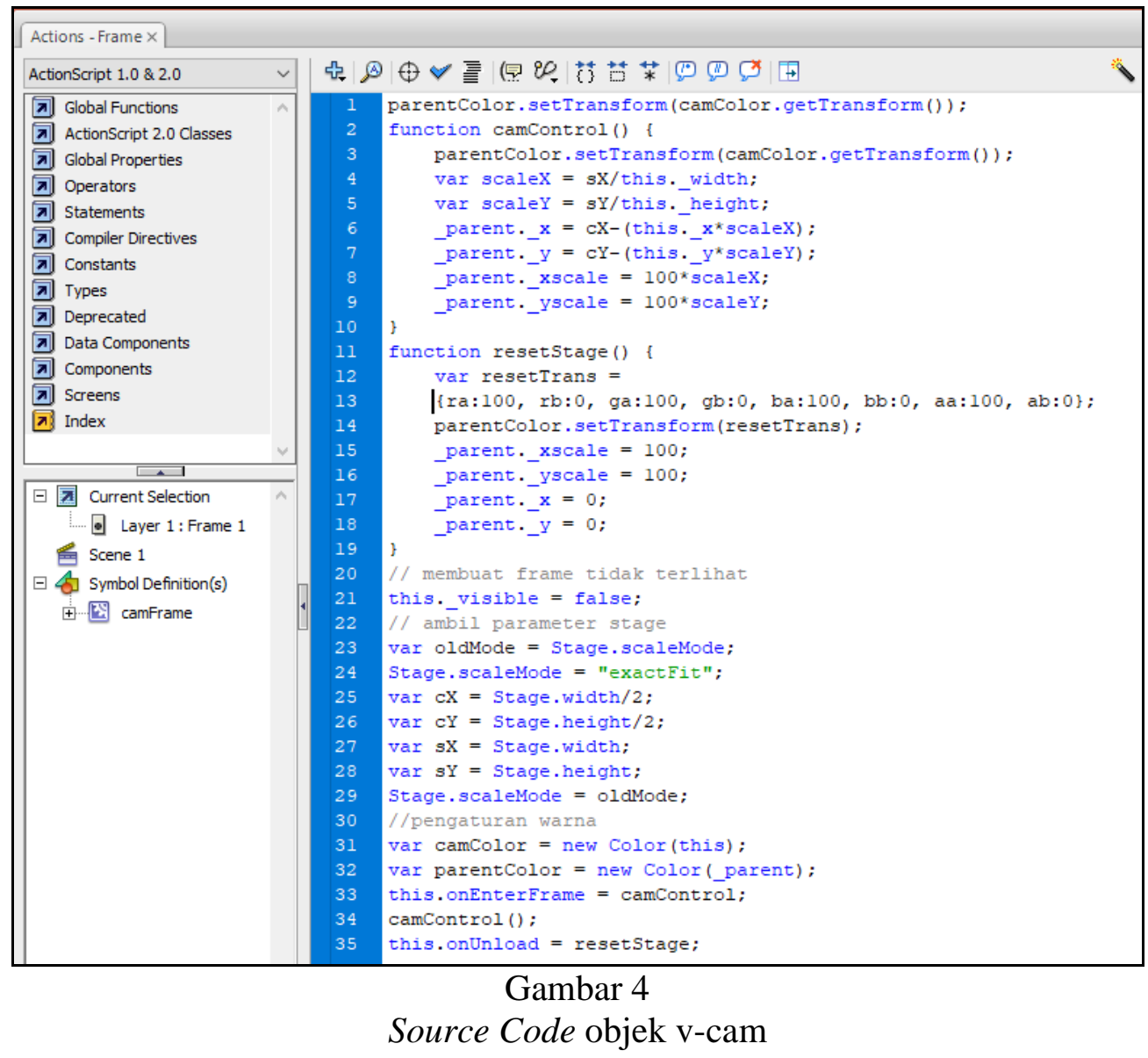

e. Tutup kotak dialog Actions, masuk kembali kedalam scene utama, perlakukan kotak seperti sebuah objek kamera yang dapat digerakan dalam lembar kerja dan animasi. Semua yang berada dalam jangkauan objek v-cam adalah sudut pandang yang kita lihat dalam hasil animasi.

\section{IMPLEMENTASI V-CAM}

Setelah mengikuti langkah-langkah pembuatan v-cam pada bagian sebelumnya, maka animator dapat menguji penggunaan objek v-cam dengan menggunakan objek tersebut untuk keperluan-keperluan dasar sebuah kamera, seperti pengujian berikut :

a. Pergerakan kamera

Gerakan kamera dapat dilakukan dari arah atas-bawah atau kanan-kiri. Pengujian dapat dilakukan dengan contoh kasus jika kamera mengikuti gerakan sebuah karakter dalam animasi.

b. Camera Scaling

Scaling dapat dilakukan secara perbesaran (zoom in) dan pengecilan (zoom out). Animator dapat memperkecil ukuran objek v-cam (untuk zoom in kamera) dan memperbesar ukuran objek v-cam (untuk zoom out) lalu melakukan tween pada timeline keyframe tertentu 


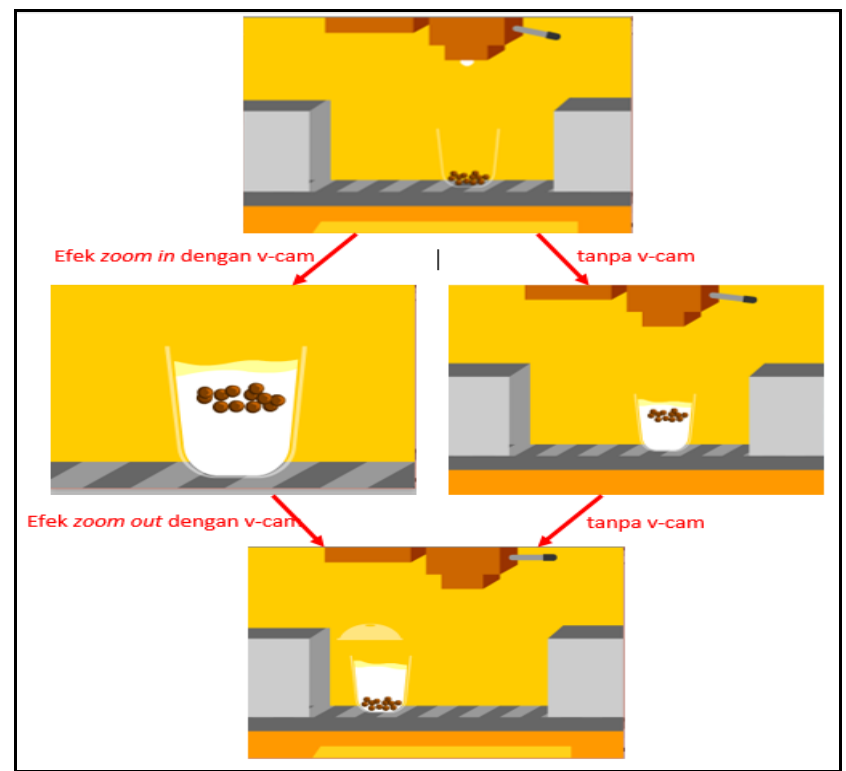

Gambar 5

Contoh hasil pemakaian v-cam pada animasi mesin minuman

c. Efek lainnya

Pada dasarnya semua objek dapat diberlakukan efek yang sama dalam Adobe Flash, seperti guncangan (geser kanan-kiri atau atas-bawah), blurring, pengaturan tint, perputaran, kecerahan, dan sebagainya. Efek tersebut juga seharusnya dapat diberlakukan terhadap objek v-cam.

Hasil uji fungsi dasar v-cam yang telah dilakukan terhadap sebuah animasi dengan tipe flash file (Action Script 3.0) berdimensi 550 x 400 pixels dapat dilihat pada tabel 1.

Tabel 1

Hasil Uji V-Cam

\begin{tabular}{|l|l|c|}
\hline \multicolumn{1}{|c|}{ Pengujian Fitur } & \multicolumn{1}{|c|}{ Ekspektasi Hasil Uji } & \multicolumn{1}{c|}{$\begin{array}{c}\text { Kesesuaian } \\
\text { Hasil Uji }\end{array}$} \\
\hline Pergerakan ke kanan & Sudut pandang bergerak ke arah kanan & Sesuai \\
\hline Pergerakan ke kiri & Sudut pandang bergerak ke arah kiri & Sesuai \\
\hline Pergerakan ke atas & Sudut pandang bergerak ke atas & Sesuai \\
\hline Pergerakan ke bawah & Sudut pandang bergerak ke bawah & Sesuai \\
\hline Zoom in & $\begin{array}{l}\text { Sudut pandang diperkecil berdasarkan } \\
\text { titik yang ditentukan }\end{array}$ & Sesuai \\
\hline Zoom out & $\begin{array}{l}\text { Sudut padang diperluas berdasarkan } \\
\text { titik yang ditentukan }\end{array}$ & Sesuai \\
\hline Guncangan & $\begin{array}{l}\text { Sudut pandang kamera seperti } \\
\text { berguncang (dengan pemberian } \\
\text { keyframe pada urutan frame layer v- } \\
\text { cam) dan menggeser posisi objek v- } \\
\text { cam pada masing-masing keyframe. }\end{array}$ & Sesuai \\
\hline Blurring & $\begin{array}{l}\text { Sudut pandang menjadi seolah-olah } \\
\text { kabur }\end{array}$ & Sesuai \\
\hline Tint & $\begin{array}{l}\text { Animasi secara keseluruhan menjadi } \\
\text { transparan atau menuju kecederungan } \\
\text { warna tertentu }\end{array}$ & \\
\hline
\end{tabular}




\begin{tabular}{|l|l|c|}
\hline Kecerahan & $\begin{array}{l}\text { Semua objek dalam sudut pandang } \\
\text { kamera menjadi lebih cerah }\end{array}$ & Sesuai \\
\hline Perputaran & $\begin{array}{l}\text { Sudut pandang seolah-olah berputar ke } \\
\text { arah tertentu }\end{array}$ & Sesuai \\
\hline
\end{tabular}

\section{KESIMPULAN}

Setelah menyelesaikan proses perancangan v-cam pada perangkat lunak Adobe Flash, kesimpulan yang dapat diambil adalah :

a. Dengan penyertaan Actions source code untuk sebuah objek persegi, objek tersebut dapat dijadikan sebuah fitur kamera virtual yang berfungsi untuk mengatur sudut pandang orang ketiga bagi viewer hasil animasi.

b. Pengerjaan animasi dengan v-cam dapat sangat mempermudah animator untuk mengatur timing dan sudut pandang kamera dibandingkan dengan pengerjaan manipulasi sudut pandang dengan cara manual.

c. Penggunaan v-cam memang bersifat opsional, setiap animator bebas menggunakan pilihan untuk menyertakan $\mathrm{v}$-cam atau tidak.

\section{DAFTAR PUSTAKA}

[1] Boy, Guy A., et al., 2010, The Virtual Camera Concept: A Third Person View, USA : Institute for Human and Machine Cognition (IHMC).

[2] Fernandez, Ibiz, 2002, Macromedia Flash Animation \& Cartooning: A creative Guide, USA : McGraw- Hill/Osborn.

[3] Setiawan, Arif Puji, M. Maulana Zia Ulhaq, 2012, Simulasi Digital : Animasi, Indonesia : XMM Media. 